Causalités aristotéliciennes

\title{
Avant-propos
}

\section{Cristina Viano}

\section{(2) OpenEdition}

\section{Journals}

Édition électronique

URL : https://journals.openedition.org/philosant/575

DOI : 10.4000/philosant.575

ISSN : 2648-2789

\section{Éditeur}

Éditions Vrin

\section{Édition imprimée}

Date de publication : 1 novembre 2016

Pagination : 7-8

ISBN : 978-2-7574-1472-9

ISSN : $1634-4561$

\section{Référence électronique}

Cristina Viano, « Avant-propos », Philosophie antique [En ligne], 16 | 2016, mis en ligne le 01 novembre 2018, consulté le 03 décembre 2022. URL : http://journals.openedition.org/philosant/575 ; DOI : https://doi.org/10.4000/philosant.575

Creative Commons - Attribution - Pas d'Utilisation Commerciale - Pas de Modification 4.0 International - CC BY-NC-ND 4.0

https://creativecommons.org/licenses/by-nc-nd/4.0/ 


\section{AVANT-PROPOS}

Les contributions réunies dans ce dossier ont été présentées et discutées, dans leur totalité ou en partie, lors du séminaire doctoral « Causes et principes », codirigé par Anca Vasiliu et Cristina Viano en 2013 à la Sorbonne, et du colloque « Le discours causal dans l'Antiquité. Enchaînements, récits, fictions $\gg\left(\right.$ Sorbonne, 23-25 octobre 2014) ${ }^{1}$.

Elles constituent un échantillonnage particulièrement représentatif de la complexité de la doctrine aristotélicienne de la causalité. Les quatre causes et leurs applications dans le corpus aristotélicien sont ici analysées selon deux perspectives spécifiques : les fonctions du mouvement et de la reproduction de l'être vivant, et les actions humaines.

En ce qui concerne la première, les thèmes de l'hylémorphisme et du finalisme sont développés autour de trois points particulièrement problématiques du corpus. Le problème général du finalisme en zoologie dans La Locomotion des animaux est traité par Pierre-Marie Morel en privilégiant une téléologie relative qui s'applique à la nature propre de l'animal. Les deux autres points concernent la reproduction sexuelle dans la Génération des animaux. David Lefebvre appréhende l'hésitation d'Aristote entre une identité analogique et une identité quasi générique entre les fonctions causales du sperma et des menstrues. De son côté, Cristina Cerami analyse la nature et la raison d'être du plaisir sexuel féminin chez Aristote et montre comment, à partir de la

1. Ce séminaire et ce colloque ont été conçus et réalisés dans le cadre d'un projet de recherche international de longue haleine, actuellement en cours sous la forme d'un GDRI intitulé «AITIA/AITIAI. Le lien causal dans le monde antique : origines, formes et transformations », dirigé par Cristina Viano (Centre Léon Robin, UMR 8061). Dans ce contexte ont été publiés les volumes suivants : C. Viano, C. Natali \& M. Zingano (éd.), Aitia I. Les quatre causes d'Aristote : origines et interprétations, Peeters, Leuven, 2013 (Aristote, Traductions et Études) ; C. Natali \& C. Viano (éd.), Aitia II. Avec ou sans Aristote : le débat sur les causes à l'âge hellénistique et impérial, Peeters, Louvain-la-Neuve, 2014 (Aristote, Traductions et Études) ; C. Darbo-Peschanski \& C. Viano (éd.), Aitia : causalité juridique, causalité philosophique, dossier de Mètis, N.S. 13 (2015) ; C. Viano (éd.), Materia e causa materiale in Aristotele e oltre, Edizioni di Storia e Letteratura, Roma, 2016 (sous presse) (Studi di Storia della Filosofia Antica). 
réception gréco-arabe, le débat concernant cette question a été relié par les successeurs d'Aristote au problème général de la cohérence de son système téléologique.

La deuxième perspective concerne les actions humaines. Marco Zingano analyse le rôle de l'intellect dans le livre III de l'Éthique à Nicomaque comme cause efficiente de l'action morale, dans le cadre de la tension entre la liberté de la décision et la fixité du caractère. Cristina Viano examine les chaînes causales qui représentent les actions humaines dans les discours judiciaires de la Rhétorique et dans les compositions tragiques de la Poétique et montre qu'elles sont orientées selon la finalité propre à chacune de ces deux technai.

Les analyses ici développées offrent un aperçu de la richesse des enjeux de la notion aristotélicienne de causalité et par conséquent du dialogue continu qui sétablira avec les successeurs d'Aristote. Nous espérons que leur lecture stimulera d'autres enquêtes car ce dialogue est encore loin d'être épuisé : aitia pollachos legetai.

Cristina Viano 